\title{
Viewpoint
}

\section{New ecological redline policy (ERP) to secure ecosystem services in China}

\author{
Yang Bai ${ }^{\mathrm{a}}$, Bo Jiang ${ }^{\mathrm{b}}$, Min Wang ${ }^{\mathrm{a}}$, Hui Li ${ }^{\mathrm{c}}$, Juha M. Alatalo ${ }^{\mathrm{d}, \mathrm{e}, *}$, Shenfa Huang ${ }^{\mathrm{a}, * *}$ \\ a Institute of Applied Ecology, Shanghai Academy of Environmental Sciences, Shanghai 200233, China \\ b Changjiang Water Resources Protection Institute, Wuhan 430051, China \\ ' School of Urban Construction and Management, Yunnan University, Kunming 650091, China \\ d Department of Biological and Environmental Sciences, College of Arts and Sciences, Qatar University, P.O. Box 2713, Doha, Qatar \\ e Department of Ecology and Genetics, Uppsala University, Campus Gotland, SE-621 67 Visby, Sweden
}

\section{A R T I C L E I N F O}

\section{Article history:}

Received 18 March 2015

Received in revised form 21 August 2015

Accepted 3 September 2015

\section{Keywords:}

Environmental policy

Ecosystem services

Beneficiary

Ecological hotspot

Management gaps

\begin{abstract}
A B S T R A C T
China is facing huge environmental problems, with its current rapid rate of urbanization and industrialization causing biodiversity loss, ecosystem degradation, and land resources degradation on a major scale. To overcome management conflicts and secure ecosystem services, China has proposed a new 'ecological redline policy' (ERP) using ecosystem services as a way to meet its targets. By giving environmental policy redline status, China is demonstrating strong commitment in its efforts to tackle environmental degradation and secure ecosystem services for the future. This is already having impact, as the Chinese Ministry of Environmental Protection and the National Development and Reform Commission are prepared to work together to implement the new environmental policy.
\end{abstract}

(c) 2015 Elsevier Ltd. All rights reserved.

\section{Introduction}

Against a background of growing awareness of the importance to society of guaranteeing continued delivery of ecosystem services, China has implemented a wide range of national policies to protect its natural ecosystems. Three previous examples are the nature reserve policy, the afforestation policy, and the zoning policy. These all play important roles in protecting natural ecosystems, although they can sometimes cause new problems (Cao, 2008) and lack rigorous targets for environmental outcomes (Bennet, 2008). For example, due to inherent design faults, heavy human disturbances, spatial mismatches, isolation, poor protection, lack of coordination and no clear boundaries, these policies are experiencing major problems. One spatial mismatch is between the spatial distribution of natural reserves and areas of high biodiversity. Many natural reserves are located in western China (e.g., the Tibet autonomous region), which has relatively low levels of biodiversity compared with other regions such as the Yunnan province.

\footnotetext{
* Corresponding author at: Department of Biological and Environmental Sciences, College of Arts and Sciences, Qatar University, P.O. Box 2713, Doha, Qatar.

** Corresponding author at: Institute of Applied Ecology, Shanghai Academy of Environmental Sciences, Shanghai 200233, China.

E-mail addresses: jalatalo@qu.edu.qa (J.M. Alatalo), shenfh@saes.ac.cn (S. Huang).
}

Due to this mismatch, approximately $30 \%$ of natural ecosystem types, $20 \%$ of wild animals, and $40 \%$ of higher plants are not included in natural reserves. In regard to isolation, China has a large number of reserves, but most are notably small and isolated. This isolation results in a lack of potential for exchange and connectivity among isolated populations, which increases the risk of species extinction and biodiversity loss. Moreover, these natural reserves provide poor protection because, despite having one of the most rigorous protection policies in China, the reserves' boundaries are frequently substantially adjusted to meet the demand of construction and other human needs. In addition, China's zoning policies were developed for strategic spatial planning and cannot be executed directly or used to guide policy making, as they lack definite conservation boundaries and do not specify clear, detailed management measures.

A new environmental policy is needed that (1) includes rigorous targets for environmental outcomes; (2) avoids spatial mismatches so that protection is provided where it is really needed (e.g., ecosystem services hotspots, eco-fragile hotspots and biodiversity hotspots); (3) states explicit spatial boundaries that identify welldefined hotspots, rather than large territories (in zoning policies); (4) attempts to increase connectivity among ecological important areas, as it is important to prevent them from becoming ecologically isolated 'islands'; and (5) strives to maintain the efficiency and persistence of the environmental policy. 
With the current rapid rate of urbanization and industrialization, as well as the growing resource shortage in the past 30 years, China is facing a number of environmental problems (Dan et al., 2014; Li et al., 2014; Zhong et al., 2013). Against this background, environmental policies must set three rigorous targets, what we call 'not targets', for ecologically important areas: that the area is not decreased; function is not reduced; and nature is not changed.

China has some of the richest biodiversity in the world and contains 17 key biodiversity protection areas (Zhong et al., 2013). These 17 areas are included in the new environmental policy being implemented today that includes definitive conservation boundaries (based on biodiversity hotspot selection) and detailed management measures for these areas. However, the habitats of many species remain under serious threat. For example, 4000 to -5000 species of higher plants, which represent $15-20 \%$ of the total number of higher plant species in China, are being threatened by extinction. China has 156 endangered species listed in the Convention on International Trade in Endangered Species, representing 25\% of the endangered species listed for the entire world (Wu et al., 2013; Zhong et al., 2013).

China is not only rich in biodiversity but also has all of the major ecosystem types outlined in the global ecosystem classification system. However, many ecosystems have been seriously damaged by human land use and urban construction. Nearly 20 million hectares (ha) of natural grassland have been broken up for crop cultivation, leading to a $30-50 \%$ reduction in grassland area compared with the 1950s. Natural forests are declining by 61,000 ha per year, and natural wetlands are disappeared at an alarming state. Since the 1980s, more than 243 lakes have been lost, and the largest swamp area in China, which is located on the Heilongjiang Sanjiang plain, has decreased in area from 5 million ha to 1.13 million ha. In addition, coastal mangrove swamps have declined from 0.05 million ha in the 1950s to 0.02 million ha at present (Dan et al., 2014). It has been estimated that $45 \%$ of the ecosystem areas in China are at high or medium ecological risk (Xu et al., 2015).

Land degradation, in the form of soil erosion, desertification, and salinization, is another serious threat to China's ecology and food security. By late 2009, more than 4.30 million $\mathrm{km}^{2}$ of land were under the threat of degradation. The total desert area, desertification area, and salinization area in China are 2.62, 1.73, and 0.17 million $\mathrm{km}^{2}$, accounting for $27.33,18.03$, and $6.59 \%$ of its national territory, respectively. Soil erosion in China amounts to more than 4.5 billion tons per annum, which is equivalent to $20 \%$ of the world's total annual erosion (Li et al., 2014).

These ecological problems are causing undesirable social and economic consequences, e.g., negative impacts on food and water security, urban heat island development, and increasing numbers of flooding disasters. Environmental complaints by ordinary citizens are increasing at an annual rate of $30 \%$. With the improvement in people's living standard and growing environmental awareness, the environmental quality of cities cannot meet people's growing environmental requirements. Furthermore, the associated reduction in human wellbeing is threatening to widen the gap between the rich and poor, which may lead to social instability.

Current government policies in China are unable to resolve the serious conflicts arising from the contradictory demands of resource owners/users and environmental managers. Resource owners/users want to sell/use as many resources as possible due to the resource shortage. However, the problem is that they do not know where to 'pay and protect'. Meanwhile, environmental managers want to protect areas that will provide vital ecosystem services for the future. Thus, there is a need to identify the most efficient and cost-beneficial areas for protection. This is a bottom-up task. For appropriate spatial resolution and ease of negotiation by beneficiaries, the identification process must be carried out at a provincial scale by the environmental protection bureau in each province. The Chinese Ministry of Environmental Protection (CMEP) can subsequently merge the results to generate a national environmental policy. In 2015, the CMEP released a standard technical document that explains in detail how to identify those areas. Meanwhile, technicians from provinces have been gathered together for several training courses organized by the CMEP on how to identify the areas. The latest training course occurred on July 15, in Nanjing, Jiangsu province. Generally, three types of hotspots should be identified, namely ecosystem services hotspots, eco-fragile hotspots, and biodiversity hotspots (Fig. 1). Indicators for ecosystem service hotspots include water storage, water quality, soil retention, and carbon sequestration. Indicators for eco-fragile hotspots include soil erosion, desertification, salinization, and geological disasters. Biodiversity hotspot identification is based on a biodiversity abundance assessment. Details of the evaluation procedure can be found in the standard technical documents released by the CMEP. On a national level, policymakers need a national ecological security network to sustain economic development and build future environments for humans. Thus, management in China is increasingly facing the question of 'Where and why to protect?'.

To resolve the current management conflict, China has proposed a new ecological redline policy (ERP) that was taken into Chinese environment protection law in 2014 and is now being implemented in all provinces. The 'ecological redline' can be defined as the ecological baseline area needed to provide ecosystem services to guarantee and maintain ecological safety, living environment safety, and biological safety. The process and criteria will follow standard technical documents provided by the CMEP. The policy to achieve this must be easy to understand and implement and must fill the knowledge gap of "where and why to protect", thus helping to solve some of the current policy problems. The novelty and importance of the proposed ERP compared with existing environmental polices is that it is attempting to use ecosystem services as a way to meet its target and that it gives environmental policy redline status. Thus, it aims to protect important eco-function areas (ecosystem service hotspots), support economic and social development, ecologically fragile areas (eco-fragile hotspots), and human living environments, and secure habitats for species (biodiversity hotspots). The number of studies on ecosystem services has increased rapidly (Fisher et al., 2009), but there is still a data gap linking ecosystem characteristics with ecosystem services. However, new ways to link these factors are being developed (Wong et al., 2015).

\section{Ecological redline policy and its application}

'Redline' means 'insurmountable boundary' in the traditional Chinese dictionary (He et al., 2014). To date, three types of redline policies have been implemented in China: the population redline (or family planning), arable land redline (or arable land minimum), and water resource redline (Yang et al., 2014) (Table 1). These are policies of the highest national priority that have had far-reaching consequences as regional and local governments do their utmost to fulfil their terms. The family planning policy has been successfully implemented since its release time, and population growth has slowed significantly since the 1980 s. The birth rate has decreased from $22.28 \%$ o (1982) to $12.08 \%$ (2013), and the natural population growth rate has decreased from $15.68 \%$ (1982) to $4.92 \%$ (2013). However, this policy has also caused some unintended consequences, for example an aging population, labour shortages, and a demographic dividend decline. It was therefore amended in 2014 to state that a couple can have two children under certain conditions.

The arable land redline policy has not yet been very successful. The trend for China's farmland is currently increasing area with 


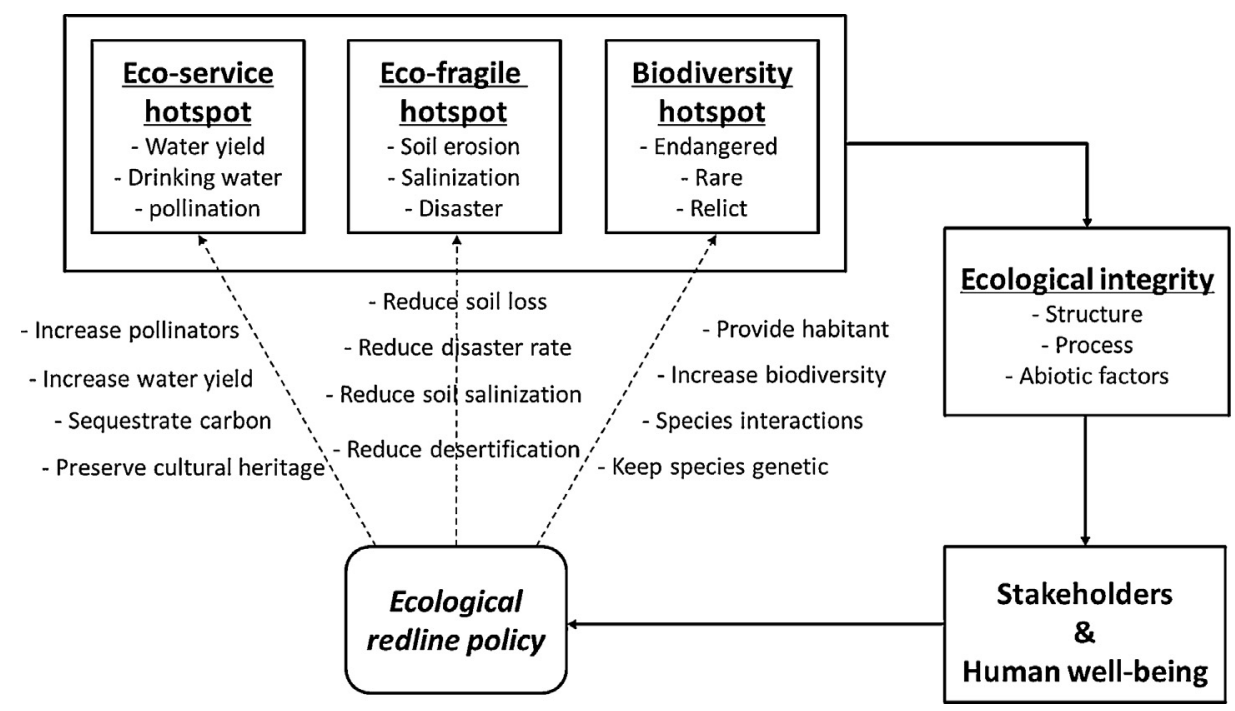

Fig. 1. The theoretical framework for China's ecological redline policy.

declining quality. China's urban sprawl has been very rapid in the past 30 years, which caused farmland area to decrease rapidly. Since the redline policy was introduced in 2009, the area of farmland has begun to gradually increase. The problem is that 'the minimum area of regular farming land' referred to in the policy is just a concept of quantity and not geographical location. Local governments usually take countermeasures of 'cultivated land requisition-compensation balance'. Cultivated land requisition often happens in highly fertile areas while compensation happens in barren areas, a process which can be referred to as 'take good, compensate from bad'. Meanwhile, nutrient and heavy metal build-up in farmland is also significant and will last for a long time. Due to these problems, the policy will be amended soon, and the Ministry of Agriculture will make the ' 120 million $\mathrm{km}^{2}$ farming land' spatially specific for protection, similar to what the ERP does. 'The redline of water resources' policy was just released and will hopefully meet its targets. The need for raising environmental policies in China to redline status has recently been recognized at a central government level (Lü et al., 2013). Giving environmental policy redline status will ensure that it is efficiently enforced throughout China. The ERP targets ecosystem protection, with the aim of protecting spatially well-defined 'ecological redline areas' (ERAs). In 2013, Chinese president Xi said his aim was 'to delineate and defend ecological redline'. The ERP was absorbed into Chinese environment protection law in 2014. Since then, the CMEP has been working on how to delineate the ecological redline. In 2014, a temporary technical document was released and the Jiangsu province was selected to be the pilot area (CMEP, 2014). In 2015, standard technical documents were released (CMEP, 2015). The policy has now been implemented in all provinces, and each province is iden- tifying its own ERP hotspots. This is already having an impact, as the CMEP and the National Development and Reform Commission (NDRC) are working together to implement the new environmental policy. The concept and aim of the ERP are rather similar to those set for natural protected areas in America, Canada, Australia, etc. The importance of the ERP is that it has the support of the state council because it has the potential to unify the different environmental agencies in China working on ecosystem protection (e.g., forests, wetlands, and lakes). The situation is different in many other countries that do not have a strong central government, such as China's. Accordingly, while some nations can only work region by region without being able to coordinate on a country level, China can manage multiple ecosystems as one.

The overall aim of the ERP is to protect the integrity of important ecosystems to secure diverse and coupled ecosystem services delivery to meet different stakeholders' needs in the ERA. The ERP has three main objectives (Fig. 1): (i) to protect important eco-function areas (e.g., ecosystem service hotspots), to deliver services such as water storage, clean drinking water, and carbon sequestration, and to maintain ecological safety to support economic and social development at both a local and national scale. (ii) To protect ecologically fragile areas (eco-fragile hotspots), to prevent soil erosion, land degradation and desertification, and to support and maintain human living environment safety, with the emphasis on local scale in all cases. (iii) To protect habitats for important species, provide habitats for species, and maintain biodiversity on a national and global scale (biodiversity hotspots). Together, these three objectives aim to build up China's national ecological security network so that it can sustain economic development and living environments. The ERP will contribute to understanding where and who

Table 1

Existing redline policies in China and their status.

\begin{tabular}{|c|c|c|c|c|}
\hline Number & Type & Meaning & Targets & Release time \\
\hline 1 & Family planning & $\sqrt{ }$ Each couple has only one child & $\begin{array}{l}\sqrt{ } \text { To slow down population growth } \\
\sqrt{ } \text { To control population size to } 1.5 \text { billion by } 2030\end{array}$ & 1982 \\
\hline 2 & Arable land minimum & $\sqrt{ }$ The minimum area of ordinary farmland & $\begin{array}{l}\sqrt{ } \text { To ensure } 120 \text { million } \mathrm{km}^{2} \text { farmland are not lost forever } \\
\sqrt{ } \text { To improve land quality }\end{array}$ & 2009 \\
\hline 3 & Water resources & $\begin{array}{l}\sqrt{ } \text { Water utilization Water use efficiency } \\
\sqrt{ } \text { Pollution discharge }\end{array}$ & $\begin{array}{l}\text { By 2030: } \\
\sqrt{ } \text { Total amount of water utilized }<700 \text { billion } \mathrm{m}^{3} \\
\sqrt{ } \text { Added value of industrial water use }<0.04 \mathrm{~m}^{3} / \mathrm{yuan} \mathrm{RMB} \text {; effective } \\
\text { coefficient of irrigative water utilization }>0.6 \\
\sqrt{ } \text { Main pollutants into lakes or rivers within their pollutant carrying } \\
\text { capacity; compliance rate in water function area }>95 \%\end{array}$ & 2012 \\
\hline
\end{tabular}


provide ecosystem services and supplies, as well as which people will benefit from this and their needs. The ERP will also help poverty alleviation, as many of the areas that are likely to be classified as ERAs are rural areas with a lower income. Local residents in ERAs will benefit from ecological compensation or other economic means to support them in preserving ecosystems.

At the same time, the ERAs need to be as small as possible considering the land resource shortage and high land conversion cost in China. Human activities exist everywhere in reality, even in the three types of hotspots targeted by the ERP. For better implementation of the ERP, the beneficiaries must recompense various local residents and land owners/users.

\section{Pros and cons of the ecological redline policy}

The ERP can help resolve the spatial mismatch in China's existing nature reserve policy. As the three different types of hotspots it targets will build up a national ecological security network, this will increase the spatial connectivity and solve some of the problems of isolation/connectivity of the protected natural areas. The ERP is suggested to become a mandatory protection policy and the strictest protection policy. All types of development and construction activities will be prohibited inside the ERA. This approach could help solve the problems of poor protection of natural reserves and afforestation policies (Ma, 2012; Wu et al., 2013). Spatially explicit boundaries that focus on protecting the hotspots, rather than the large territories covered by the existing policies (He et al., 2014), will allow the ERP to be easily understood and executed. A national-scale ERP hotspot map is planned to be released in 2016. The hotspots are mainly distributed in the Tibet autonomous region, Qinhai province, Sichuan province, Yunnan province, Inner Mongolia autonomous region, and Fujian province. Our calculations on a national scale indicate that the $30-35 \%$ of the Chinese national territorial areas will be identified as ecosystem hotspots and that these can preserve nearly $85 \%$ of ecosystem services. However, because of the varying ecological importance on a spatial scale, the $30-35 \%$ proportion of area is likely to differ among the provinces. In the Sichuan and Fujian provinces, for example, the proportion may reach $50 \%$. In contrast, the proportion is likely to be less than $10 \%$ in Shanghai. The Jiangsu province, the pilot area, has released information on its ERP hotspots, which account for $20 \%$ of its territorial area. This will solve the problems related to the existing zoning policy not having clear spatial boundaries (Yang et al., 2014) and therefore being difficult to implement. Moreover, as each hotspot will provide its own specific and coupled ecosystem services, stakeholders and departments can be expected to know why an area should be protected and what ecosystem services it will provide. Potential limitations include: (1) large compensation fees; (2) the long process of implementing ERP, which cannot occur right away, as such developments as factories, tourist spots, and residential areas already exist. The legislation around ERP has to be strengthened, and stakeholders' awareness and perceptions need to be clarified. We anticipate that a period of $10-15$ years will be needed for benign implementation of the ERP to form a national ecological security network.

As the ERP is relatively easy to understand and has obvious benefits for stakeholders, it has the potential to be successfully implemented in China. The redline status sends the signal to regional and local governments that the ERP is a top priority, which will ensure that they strive to strictly enforce it similarly to the redline policy on family planning. The ERP has ambitious targets and has the potential to improve ecosystem protection in China. However, having an ambitious target is not enough, as many policy challenges exist. To ensure that the ERP is maintained, there is a need to identify how to link ecosystem services to policy implementation as well as how to measure ecosystem services and their contribution to society. Perhaps the most difficult administrative challenge for the ERP is maintaining its efficiency and persistence in filling the management gap in the long run. Other research challenges are the need to develop new indicators to evaluate the protection effect of the ERP, to improve connectivity among ERAs, and to prevent them from becoming ecologically isolated islands.

Overall, it is clear that incorporating the ERP into national ecological protection in China will generate many benefits for stakeholders, contribute to secure ecosystems, and fill the management gap that exists between current environmental problems and policies. The CMEP and the NDRC are prepared to work together to implement the new environmental policy. The coming $10-15$ years will be exciting with regard to the implementation of China's ERP.

\section{Conflict of interest}

The authors declare no conflict of interest.

\section{Acknowledgments}

We gratefully acknowledge the financial support of National Natural Science Foundation of China (41501580). We thank Christina P. Wong for helpful comments on an earlier draft.

We thank two anonymous reviewers for their constructive comments that improved the manuscript.

\section{References}

Bennet, M.T., 2008. China's sloping land conversion program: institutional innovation or business as usual. Ecol. Econ. 4, 699-711.

Cao, S.X., 2008. Why large-scale afforestation efforts in China have failed to solve the desertification problem. Environ. Sci. Technol. 42, 1826-1831.

CMEP, 2015. Technology guide for ecological red line. (In Chinese). (No. 2015.5). Chinese Ministry of Environmental Protection.

CMEP, 2014. Technology guide for ecological red line (temporary). (In Chinese) (No. 2014.1). Chinese ministry of Environmental Protection.

Dan, X.Q., Bao, D.M., Dan, W.Y., Wu, H.J., Wu, Z.B., 2014. Discussion on the identification and management of wetland boundary. Cent. South For: Inventory Plan. 33, 61-66.

Fisher, B., Turner, R.K., Morling, P., 2009. Defining and classifying ecosystem services for decision making. Ecol. Econ. 68, 643-653.

He, Y., Yang, W.R., Guo, R., Zhao, D., 2014. Designation and management of urban ecological redline. Beijing Plan. Rev. 2, 21-25.

Li, Z., Ke, S.F., Liu, Y., Song, Z.M., Wu, Y.S., 2014. The achievements and experiences of land degradation prevention and control in western China: a case study of PRC-GEF partnership on land degradation in dryland ecosystems. J. Beijing For Univ. Soc. Sci. 13, 71-76.

Lü, Y., Ma, Z., Zhang, L., Fu, B., Gao, G., 2013. Redlines for the greening of China. Environ. Sci. Policy 33, 346-353.

Ma, K.P., 2012. A mini review on the advancement in biodiversity research in China in 2011. Biodivers. Sci. 20, 1-2.

Wong, C.P., Jiang, B., Kinzig, A.P., Lee, K.N., Ouyang, Z., 2015. Linking ecosystem characteristics to final ecosystem services for public policy. Ecol. Lett. 18, 108-118, http://dx.doi.org/10.1111/ele.12389.

Wu, J.Y., Xue, D.Y., Zhao, F.W., Wang, Y.J., 2013. Progress of the study on investigation and conservation of biodiversity in China. J. Ecol. Rural Environ. 29, 146-151.

Xu, X., Xu, L., Yan, L., Ma, L., Lu, Y., 2015. Integrated regional ecological risk assessment of multi-ecosystems under multi-disasters: a case study of China. Environ. Earth Sci., 1-12, http://dx.doi.org/10.1007/s12665-015-4079-2.

Yang, B.J., Gao, J.X., Zou, C.X., 2014. The strategic significance of drawing the ecological protection red line. China Dev. 14, 1-4.

Zhong, M.H., Ma, H.Y., Ling, Y.H., 2013. Status quo, deficient and strategy in biological diversity conservation of China. J. Liupanshui Norm. Univ. 25, 19-23. 